\title{
Diario del Compromiso de Caspe, 1412. Restauración y conservación de un documento manuscrito
}

\author{
Luciano Pardo Pardo | Servei de Biblioteques i Documentació, Universitat de \\ València \\ Clodoaldo Roldán García | Instituto de Ciencia de los Materiales, Universitat de \\ València
}

URL de la contribución <www.iaph.es/revistaph/index.php/revistaph/article/view/3414>

\section{RESUMEN}

El Diari del Compromís de Casp, es un valioso documento para la historia de la Corona de Aragón. En este artículo se expone el proceso y los criterios marcados para su restauración. Los tratamientos comunes como el lavado, desacidificación, reintegración mecánica, etc. pueden modificar profunda e irreversiblemente las características físicas y químicas de los materiales que forman el documento. Sabemos que su integridad contiene valores que trascienden el mero conjunto de elementos que lo conforman y que su alteración puede afectar a la singularidad del documento; por tanto su preservación es tan necesaria como la del resto de elementos, costura, encuadernación, guardas, decoración, etc. Por esta razón es importante valorar la aplicación y repercusión de cada tratamiento, y optar en la medida de lo posible por intervenciones localizadas y técnicas alternativas menos agresivas, como la reintegración mecánica del soporte en seco.

Sin embargo, la perdurabilidad de las obras no está garantizada con la restauración. Para aumentar la esperanza de vida de nuestro patrimonio es preciso el control y la mejora de las condiciones de conservación. El Servei de Biblioteques i Documentació Universitat de València ha venido desarrollando a lo largo de los años un plan integral de preservación que constituye la clave de su labor.

\section{Palabras clave}

Intervención | Libros | Manuscritos | Patrimonio documental | Reintegración mecánica en seco | Restauración | Universitat de València. Instituto de Ciencias de los Materiales | Universitat de València. Servei de Biblioteques i Documentació | 


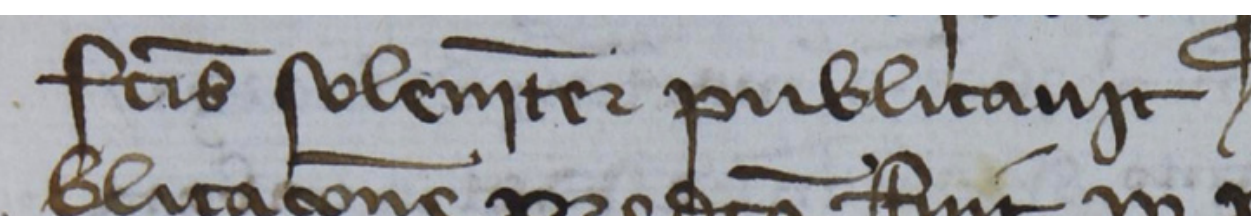

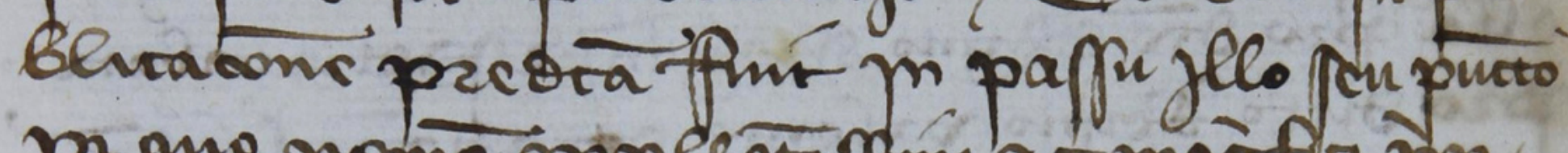

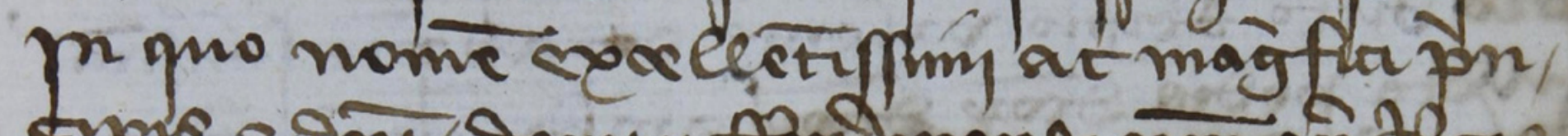

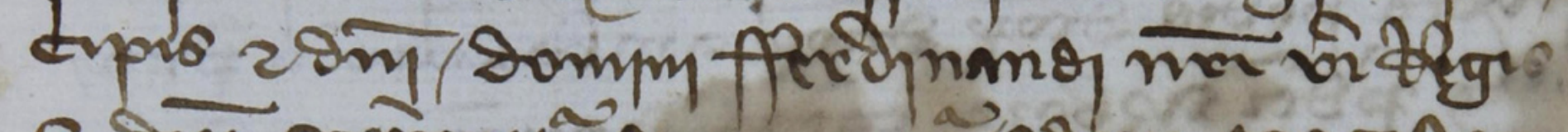

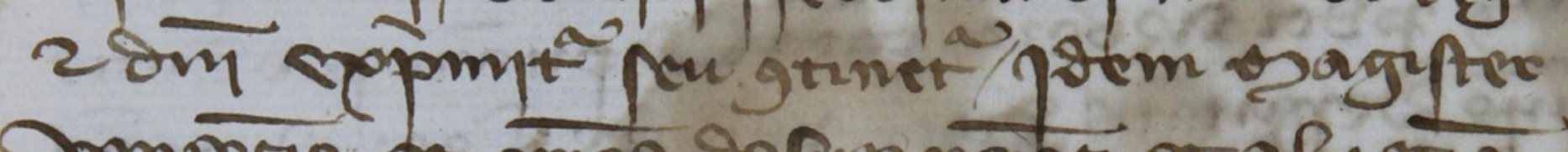

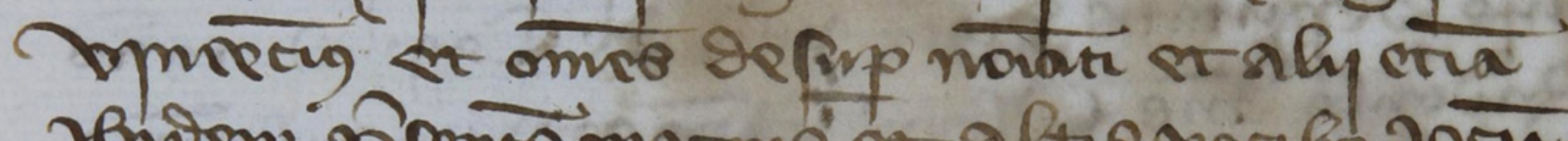

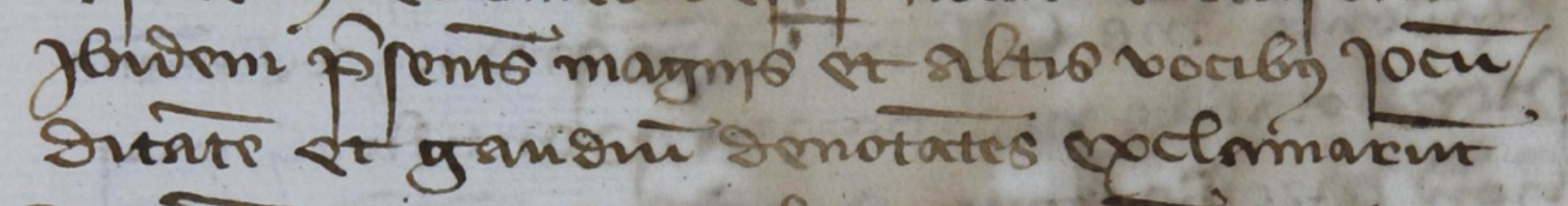

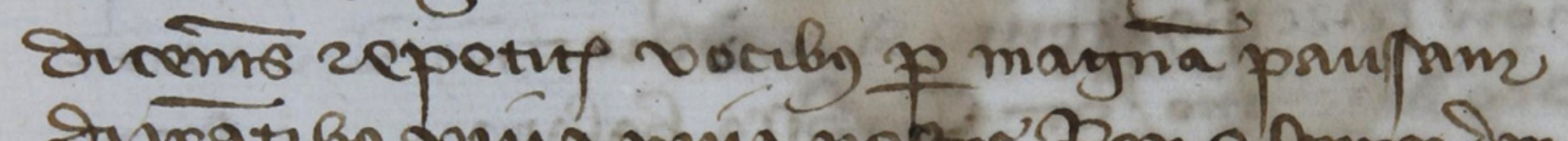

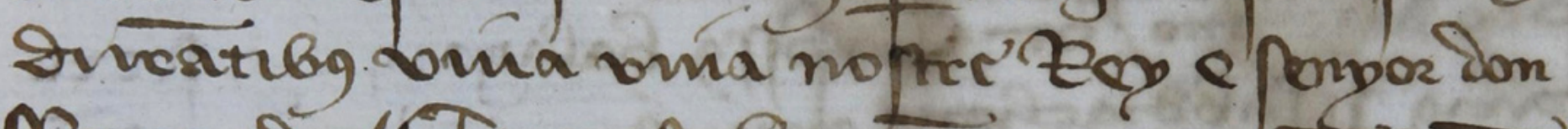

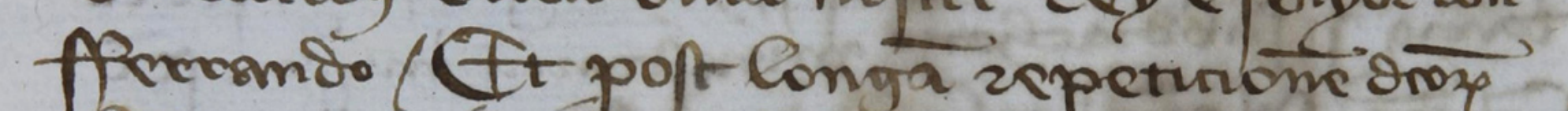

revista ph Instituto Andaluz del Patrimonio Histórico nº 85 abril 2015 pp. 160-183 | PROYECTOS Y ACTUACIONES 


\section{HISTORIA DEL DOCUMENTO}

Sobre la cubierta delantera del manuscrito $n .{ }^{\circ} 40$, conservado en la Biblioteca Histórica de la Universitat de València, puede leerse la siguiente anotación: "Proces de la eleccio del Rey Fernando I en Arago Mccccx"

El documento contiene los acuerdos alcanzados en Alcañiz y el diario de sesiones con las deliberaciones del compromiso de Caspe. Además incluye una introducción referida a la muerte del rey Martín I el Humano. Su fallecimiento sin descendientes directos, el 31 de mayo de 1410, fue el inicio de un largo proceso para la elección del sucesor (DUALDE et ál., 1971; SOLDEVILA, 1971).

El 15 de febrero de 1412 quedó establecido en la Concordia de Alcañiz el procedimiento que debía seguirse para la elección del nuevo rey y, entre otros, se convino que nueve compromisarios debían reunirse el 29 de marzo de 1412 en Caspe para comenzar las deliberaciones.

1

Fragmento del Diario del compromiso de Caspe (Universitat de València. Biblioteca Histórica, Ms. 40, f.138r-v)
"Del Regne d'Aragó: lo reverent pare en Christ lo senyor Bisbe d'Oscha, lo honorable mossén Francesch d'Aranda, lo honorable en Berenguer de Bardaxí.

Del Regne de València: lo reverent pare en Christ mestre Vicent Ferrer, mestre en la santa Theologia; lo reverent pare en Christ mossén Bonifaci Ferrer, Don de l'Orde de Cartoxa; lo honorable micer Jener Rabaça, cavaller e doctor en leys.

Del Principat de Catalunya: lo reverent pare en Christ lo senyor Arquebisbe de Tarragona, lo honorable micer Guillem de Vallsecha, doctor en leys; lo honorable micer Bernat de Gualbes, doctor en cascun dret"1.

El 29 de marzo de 1412 se iniciaron las deliberaciones de los compromisarios que finalizaron el 25 de junio de 1412 con la elección de Fernando de Castilla como rey de la Corona de Aragón. El 28 de junio de 1412, en un acto solemne ante los representantes de todos los territorios y de los aspirantes, fray Vicente Ferrer leyó el acta con el acuerdo alcanzado por los nueve compromisarios (imagen 1).

El manuscrito de la Universitat de València fue catalogado por el bibliotecario Marcelino Gutiérrez del Caño como perteneciente al siglo XVI. Sin embargo, el profesor Francisco Gimeno ha confirmado que el manuscrito de la Universitat de València es uno de los diarios de las deliberaciones del Compromiso de Caspe. Este documento se escribió al mismo tiempo que el ejemplar del archivo de la catedral de Segorbe. Tanto su contenido como su materialidad evidencian que se trata de dos copias realizadas por los notarios que estuvieron al servicio de los compromisarios reunidos en Caspe (GIMENO, 2009). 


\section{ANÁLISIS Y DESCRIPCIÓN DE LA OBRA}

\section{Encuadernación}

El documento presenta una encuadernación de archivo. Los cuadernillos van cosidos directamente sobre la cubierta de pergamino en la zona del lomo reforzado con bandas de piel (imagen 2A); ausencia de cabezadas, guardas y pastas; elaboración de cierres con tiras de piel, así como pestañas de protección en el corte delantero (imagen 2B). En la cubierta y en el lomo se encuentra manuscrito el título, mediante una escritura gótica textual redondeada empleada en la copia y transcripción de libros de privilegios y corales, así como en libros litúrgicos (GIMENO, 2009). La escritura del título de la cubierta pudo inducir a la datación tardía de este título como perteneciente al siglo XVI. El cuerpo del documento lo componen siete cuadernillos, los seis primeros formados por media mano antigua (12 pliegos o bifolios) y el séptimo por un sexterno (6 pliegos).

Estructura del documento:

A) Título a modo de resumen en el f. $1 r$ "lesus. Processus actuum ...".

B) Entre los ff. 2r_3v se inserta un prólogo referido a la muerte del rey Martín el 31 del mes de mayo de 1410.

C) Entre los ff. 3v_11v el texto íntegro de la Concordia de Alcañiz, datada el 15 de febrero del año 1412, concluida la exposición de los acuerdos alcanzados.

D) Continúan en blanco los ff. 12r_15v.

E) En el f. 16r comienza el diario de sesiones que termina en el f. 150v. Las sesiones comenzaron el 29 de marzo del año 1412 y finalizaron el día de la proclamación del infante don Fernando el 28 de junio de 1412.

F) Cuadernos del $2 .^{\circ}$ al $6 .^{\circ}$ aparecen numerados en el primer folio de cada uno con números romanos: f. 25r: ij; f. 49r: iij; f. 73r: iiij; f. 97r: v; f. 121r: vj. En el manuscrito conservado en el archivo de la catedral de Segorbe también aparece este tipo de numeración en los cuadernos que lo integran.

\section{Costura}

Considerando la gran cantidad de perforaciones que contiene el pliegue de los cuadernillos, y teniendo en cuenta que la mayoría no se corresponden con los de la cubierta, podemos deducir que la costura no es la original aunque el pergamino podría ser reutilizado. A juzgar por la escritura de la cubierta podría tratarse de una encuadernación posterior, del siglo XVI. Encontramos perforaciones con fragmentos de hilo grueso de la costura actual en el primer y el séptimo cuadernillo, así como dos cabos que salen al exterior en el primero y tercer cuadernillo (imagen 2C). Existen otras perforaciones con restos de hilo fino, situadas a una distancia irregular y diferente de la costura actual, lo que puede indicar que se trata de una costura individual de los cuadernillos para su comercialización a modo de cuaderno. Estos fragmentos se 
2. Análisis de materiales y técnicas

A. Huellas de la costura y restos de refuerzos de piel en el lomo.

B. Ausencia de cabezadas, guardas y pastas, pestañas en el corte de delante y restos de piel de los cierres.

C. Estructura de la costura.

D. Imagen por transparencia: tamaño de la forma y distribución de corondeles, puntizones y filigrana (f. 12-13).

E. Filigrana (f. 12-13): flor de lis, similar a la número 7269 de Briquet.

F. Filigrana (f. 148-153): busto de ciervo, similar a la número 3278 de Briquet.

G. Características originales como la textura y satinado del papel puede observarse a simple vista (f. $12 v-13 r$ )

H. Aspecto tinta empalidecida f. $145 r$

I. Aspecto tinta intensa.

| fotos Luciano Pardo
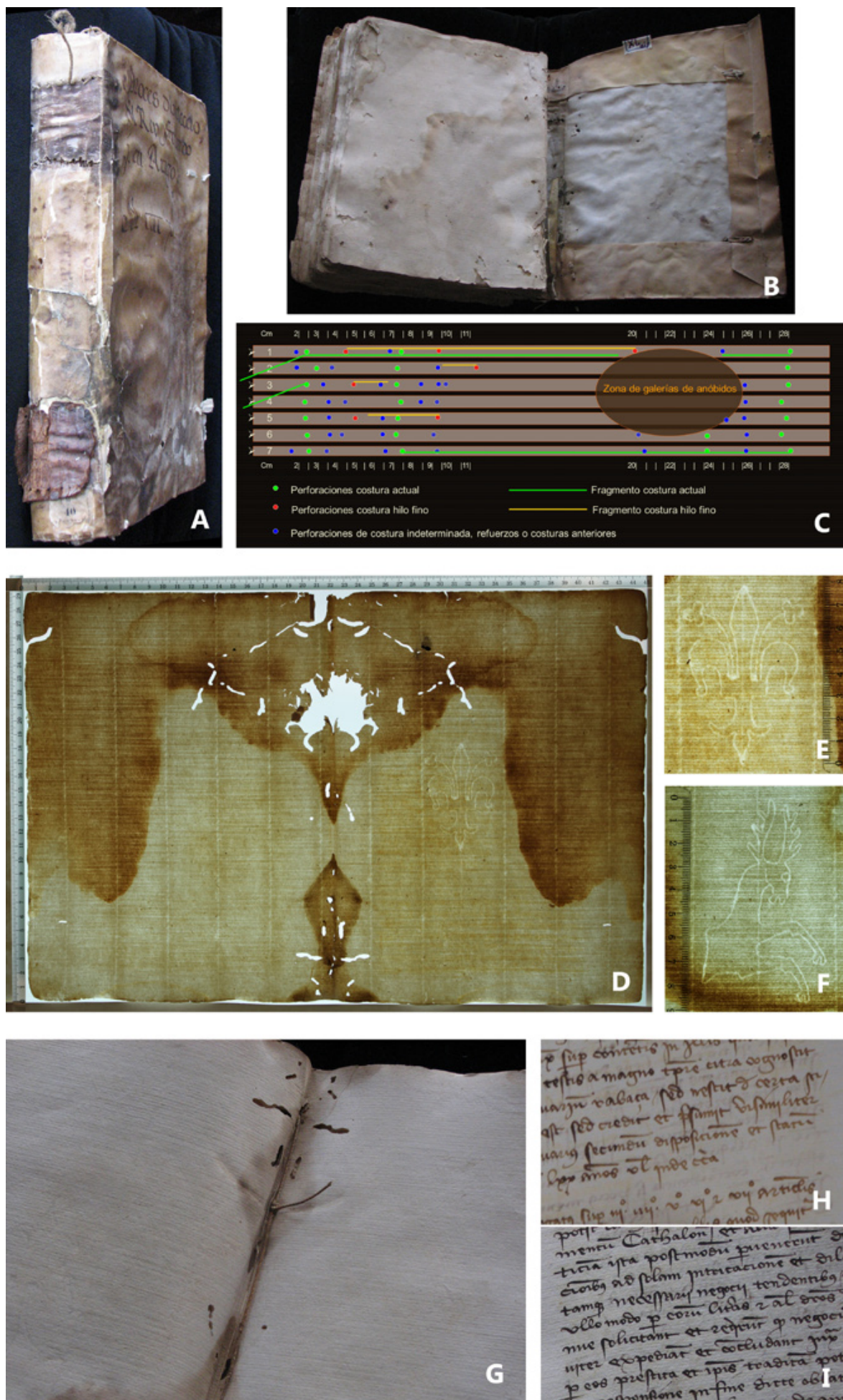
han localizado en los tres primeros cuadernillos y en el quinto. El resto de perforaciones puede deberse a una costura anterior y a diferentes refuerzos efectuados a lo largo de los años.

\section{Soporte}

Se trata de un papel de trapos (la fibra más utilizada en esta época es el lino) de fabricación artesanal, con unas dimensiones de 300 × $450 \mathrm{~mm}$ que corresponden al tamaño completo de la forma (imagen 2D). Se aprecian 13 corondeles con una distancia entre ellos de $37 \mathrm{~mm}$, excepto los de ambos extremos $(25 \mathrm{~mm})$ y los que soportan la filigrana $(30 \mathrm{~mm})$. La densidad de puntizones es de $7 / \mathrm{cm}$ a $8 / \mathrm{cm}$. En los corondeles se pueden apreciar las líneas oblicuas de fijación de los puntizones (imagen 2E, F). A simple vista pueden observarse características del papel como la textura del verjurado 0 el brillo superficial del satinado (imagen 2G).

Encontramos dos modelos de filigranas en el papel. La primera es una flor de lis similar a la número 7269 (imagen 2E), localizada en manuscritos con textos datados entre 1399 y 1403 (BRIQUET, 1966: t. 2, 399) y la otra un busto de ciervo similar a la número 3278 (imagen 2F), localizada en manuscritos con textos datados entre 1395 y 1402 (BRIQUET, 1966: t. 1, 219).

\section{Elementos sustentados}

\section{Escritura}

El documento está escrito a línea tirada con una cursiva notarial utilizada en ambiente documental. En la ejecución caligráfica han desaparecido el contraste de trazos finos y gruesos de la escritura gótica (GIMENO, 2009).

El variado aspecto que presentan las tintas a través del documento, tanto en intensidad como en color, hacen pensar que podía tratarse de tintas de diversa naturaleza (imagen $2 \mathrm{H}, \mathrm{I}$ ). Con objeto de determinar su composición se solicitó la colaboración del Instituto de Ciencia de los Materiales (ICMUV) de la Universitat de València, en el que se realizan estudios e investigaciones para la identificación de compuestos inorgánicos, mediante la realización de análisis no destructivos.

Los análisis se realizaron in situ (ROLDÁN, 2011) (imagen 3A) mediante un espectrómetro EDXRF portátil (fluorescencia de rayos-X dispersiva en energía) (ARDID et ál., 2004; FERRERO et ál., 2004). En la medición de un punto con tinta se mezclan los componentes de la propia tinta con los del soporte, pergamino o papel, para distinguirlos se realizaron mediciones de soporte con tinta y libre de tinta. Se seleccionaron 29 puntos de medida: zonas sólo de soporte (papel y pergamino), zonas de papel con manchas y zonas con tintas de diferente aspecto en ambos soportes. Los espectros de 
3. Análisis EDXRF

A. Equipo de análisis EDXRF compuesto por: fuente de excitación de $30 \mathrm{kV}$ y $1 \mathrm{~mA}$, con ánodo de plata. Detector: Si-PIN (FWHM 180 eV @ $5.9 \mathrm{MeV}$ ).

B. Espectro EDXRF del soporte-papel del f. 10v (Fol_10v)

C. Espectro EDXRF del soporte-pergamino.

D. Comparación de una zona de papel sin machas y una zona de papel con mancha oscura debida corrimientos de piel de la encuadernación (Fol_02r). E. Espectro EDXRF de las tintas del f. 59r (Fol 59r).

F. Comparación de la tinta de una palabra tachada y otra sin tachar en f. 3r (Fol_03r).

G. Áreas de las líneas de fluorescencia de $\mathrm{Fe}+\mathrm{S}+\mathrm{K}$ frente al área de $\mathrm{Ca}$ para las tintas analizadas en Ms. 40. Aparecen tres grupos: en verde las tintas del cuerpo del documento, en azul la tinta de la encuadernación y en rojo la tinta del f. 1r (Fol_01r).

| fotos Clodoaldo Roldán

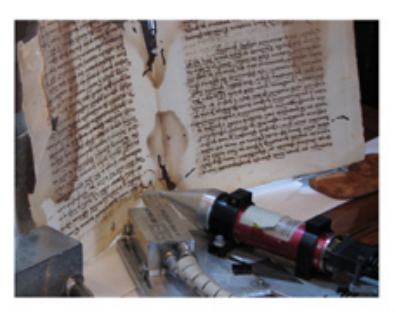

A
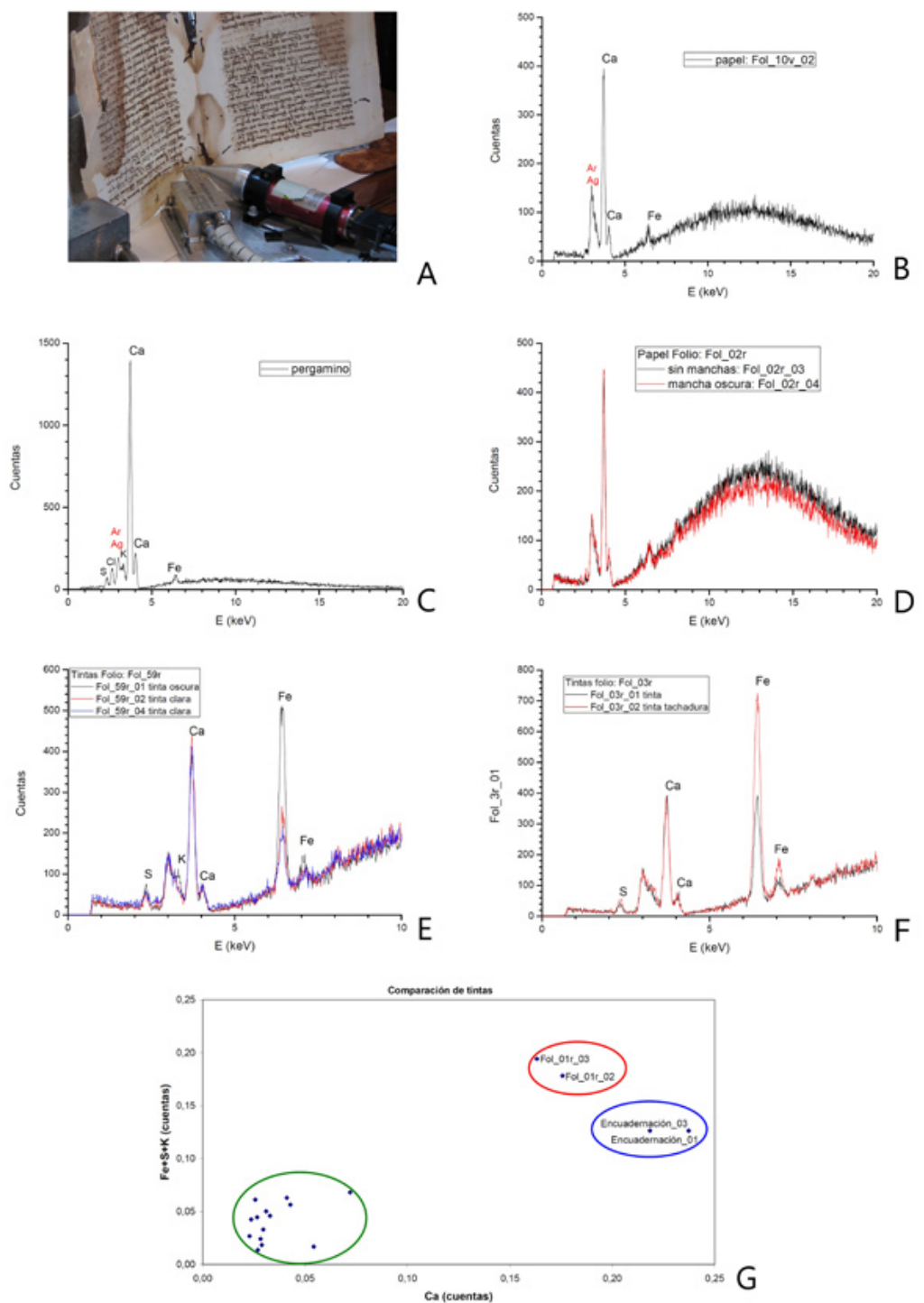

fluorescencia se registraron con potencial de excitación de $30 \mathrm{kV}$, intensidad de corriente de 0.005 mA y tiempo de adquisición de 180 segundos.

\section{Composición del soporte de papel y pergamino}

Los análisis EDXRF sugieren un papel a base de fibras vegetales con un alto contenido en $\mathrm{Ca}$ y la presencia minoritaria de Fe, existiendo una clara correlación entre las cantidades detectadas de estos dos elementos. La can- 

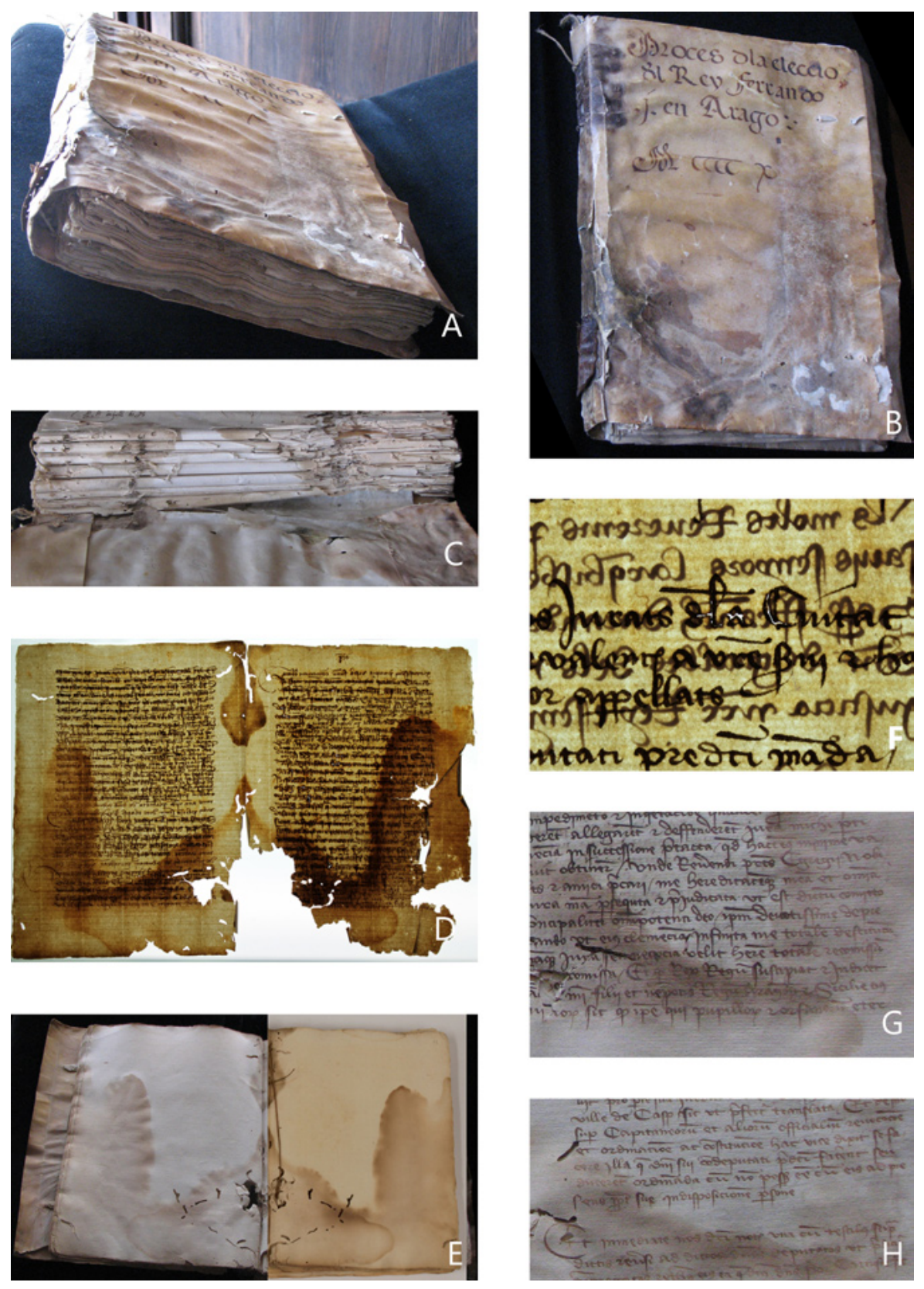

4. Estado de conservación

A. Cubierta: ondulaciones causadas por la humedad.

B. Cubierta: zona contraída, manchas, desgarros, lagunas, pérdidas.

C. Interior de la cubierta, cuadernillos descosidos, zona de ataque de anóbidos.

D. Imagen por transparencia f. $23 v-2 r$ con manchas de humedad, grietas, erosiones, lagunas, galerías de insectos, etc.

E. Manchas de humedad con ondulaciones en los límites de la mancha y aureolas dentro de aureolas f. $13 \mathrm{r}$ y $14 \mathrm{v}$.

F. Imagen por transparencia: pequeñas perforaciones en la tinta f. 2.

G. Zonas de tinta disuelta f. 21 .

H. Zonas de tinta empalidecida f. 37r.

| fotos Luciano Pardo
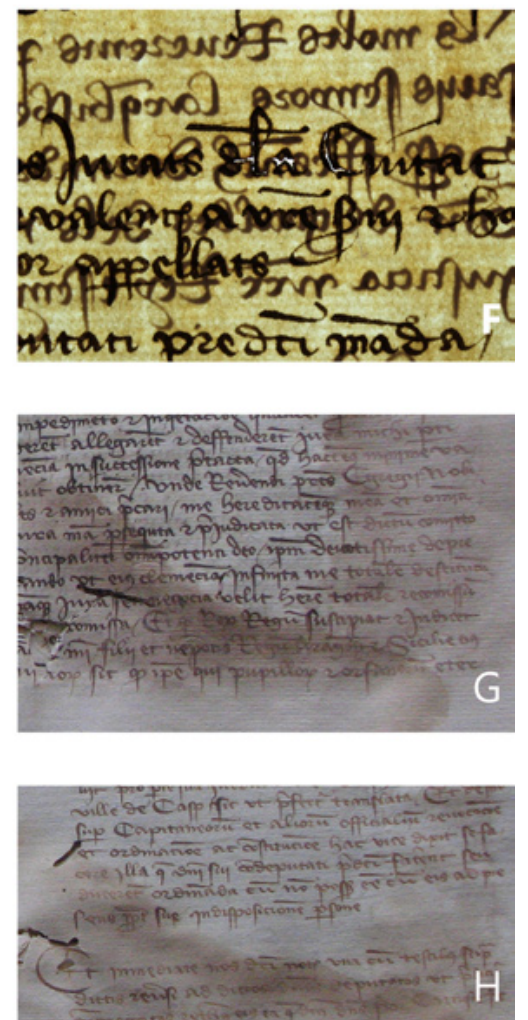

tidad de Ca relativa al Fe es notablemente superior en el pergamino que en el papel (imagen 3B, C).

Las manchas analizadas se sitúan en los pliegues de los cuadernillos y corresponden al desteñido de la piel de refuerzo. Tras su análisis no se observó diferencias entre zonas de papel sin mancha y zonas de papel con manchas (imagen 3D). 


\section{Diferencias entre tintas intensas, pálidas y zonas perforadas}

Los elementos característicos de las tintas son $\mathrm{Fe}$, S y K, por lo que se pueden clasificar como tintas ferrogálicas. Las tintas analizadas no presentan, en ningún caso, otros elementos diferenciadores que permitan realizar una discriminación temporal o de la materia prima utilizada. Las concentraciones de estos elementos en las tintas varían según los puntos de medida, pero estas variaciones pueden estar asociadas a la inhomogeneidad de la materia prima (tinta) empleada. Las tintas más oscuras presentan una mayor intensidad de las líneas de fluorescencia del Fe que las tintas claras (imagen $3 \mathrm{E})$. Las tintas de las tachaduras tampoco presentan un patrón de fluorescencia que permita discriminarlas (imagen $3 \mathrm{~F}$ ).

Sin embargo, las tintas empleadas en el pergamino de la encuadernación y en el $\mathrm{f}$. $1 \mathrm{r}$ constituyen grupos diferenciados entre sí y del resto de tintas (imagen 3G). Si tomamos como referencia las áreas de fluorescencia del Ca (elemento ligado al papel) y las comparamos con la suma de las áreas de los tres electos característicos de las tintas $(\mathrm{Fe}+\mathrm{S}+\mathrm{K})$, aparecen grupos diferenciados que quedan reflejados en la representación gráfica. Efectuando un análisis global de las tintas, podemos inferir que las tintas usadas en el pergamino de la encuadernación y en el f. $1 \mathrm{r}$ se diferencian del resto de tintas, no porque haya elementos discriminadores, sino por las proporciones en las que se encuentran dichos elementos.

\section{ANÁLISIS DEL GRADO DE DETERIORO}

\section{Análisis y diagnosis del estado de conservación general del documento}

Una vez conocidos los materiales y las técnicas de creación del documento se analizó el estado de conservación identificando el tipo de daño, localización, extensión y posible causa (véase tabla 1).

Las aureolas de humedad afectan a todo el cuerpo del documento con grandes zonas en el primer cuadernillo que disminuyen progresivamente hasta el sexto cuadernillo y aumentan de nuevo en el séptimo. Se aprecian aureolas dentro de aureolas (imagen 4E), lo que indica que el documento ha podido sufrir más de un desastre.

La degradación que presenta el documento en la actualidad se debe sobre todo a dos causas circunstanciales desencadenantes, el contacto prolongado con la humedad y la infestación de insectos bibliófagos. Ambas circunstancias no están relacionadas y han podido producirse en distintas ocasiones. El contacto prolongado con la humedad ha provocado la disolución y arrastre de cargas, aprestos y tintas, debilitando el papel y produciendo grandes 


\begin{tabular}{|c|c|c|}
\hline & $\begin{array}{l}\text { Encuadernación } \\
\text { (imágenes 4A-C) }\end{array}$ & $\begin{array}{l}\text { Cuerpo del documento } \\
\text { (imágenes 4D-E) }\end{array}$ \\
\hline Manchas & $\begin{array}{l}\text { Causadas por la humedad, microorganismos y } \\
\text { desteñido de refuerzos de piel }\end{array}$ & $\begin{array}{l}\text { Abundantes y extensas aureolas de humedad } \\
\text { y desteñido de piel. Algunas de cera y } \\
\text { excrementos de insectos }\end{array}$ \\
\hline Deformaciones & $\begin{array}{l}\text { Contracción de las zonas afectadas por } \\
\text { la humedad que han provocado grandes } \\
\text { ondulaciones, destacando las perpendiculares } \\
\text { al lomo en la cubierta }\end{array}$ & $\begin{array}{l}\text { Ondulaciones causadas por la humedad, más } \\
\text { pronunciadas en el contorno de las aureolas }\end{array}$ \\
\hline Resistencia & $\begin{array}{l}\text { Rigidez generalizada causada por la } \\
\text { deshidratación }\end{array}$ & $\begin{array}{l}\text { Fragilidad notable en zonas afectadas por } \\
\text { la humedad, principalmente en las primeras } \\
\text { hojas }\end{array}$ \\
\hline Roturas & $\begin{array}{l}\text { Grietas y desgarros en la zona del lomo y } \\
\text { costura, erosiones }\end{array}$ & $\begin{array}{l}\text { Grietas, desgarros y erosiones más } \\
\text { concentradas en zonas de humedad }\end{array}$ \\
\hline Lagunas & En el lomo y en la zona inferior de la cubierta & $\begin{array}{l}\text { Grandes zonas perdidas de soporte en los } \\
\text { primeros folios, causados en su momento por } \\
\text { la humedad y la actividad de microorganismos. } \\
\text { Galerías de anóbidos en todo el documento } \\
\text { principalmente en la zona del lomo }\end{array}$ \\
\hline $\begin{array}{l}\text { Elementos } \\
\text { desaparecidos }\end{array}$ & Costura, cierres, refuerzo de piel & Folio 155 cortado \\
\hline $\begin{array}{l}\text { Restauraciones } \\
\text { anteriores }\end{array}$ & Parche de pergamino en el lomo & \\
\hline
\end{tabular}

manchas. También ha favorecido el desarrollo de microorganismos que desTabla 1. Análisis y diagnosis del estado de conservación general del documento truyen la celulosa por hidrólisis enzimática, produciendo fragilidad, grietas, desgarros y pérdidas de soporte (en la actualidad no se aprecia actividad de la microbiota que en su momento pudo degradar la celulosa).

Por último, la dilatación-contracción del soporte ha producido deformaciones del soporte y rotura de la costura.

El tamaño de las galerías indica la acción de anóbidos. Las galerías se localizan principalmente en la parte inferior del lomo y han provocado la pérdida de soporte y la desaparición de parte de la costura. Actualmente no hay indicio alguno de la presencia de insectos en ningún estado de su metamorfosis.

Ambas causas de deterioro podrían describirse como procesos de degradación estable, es decir, se produjeron en un momento determinado y posteriormente se detuvieron al desaparecer las causas. Sin embargo la manipulación del documento frágil y desencuadernado ha tenido como consecuencia final, la aparición de desgarros y la pérdida de fragmentos de soporte, algunos con grafía.

\section{Análisis y diagnosis de las tintas}

La causa inherente de degradación más importante en los documentos de esta época es la tinta. Por esta razón la evaluación de su nivel de deterioro 

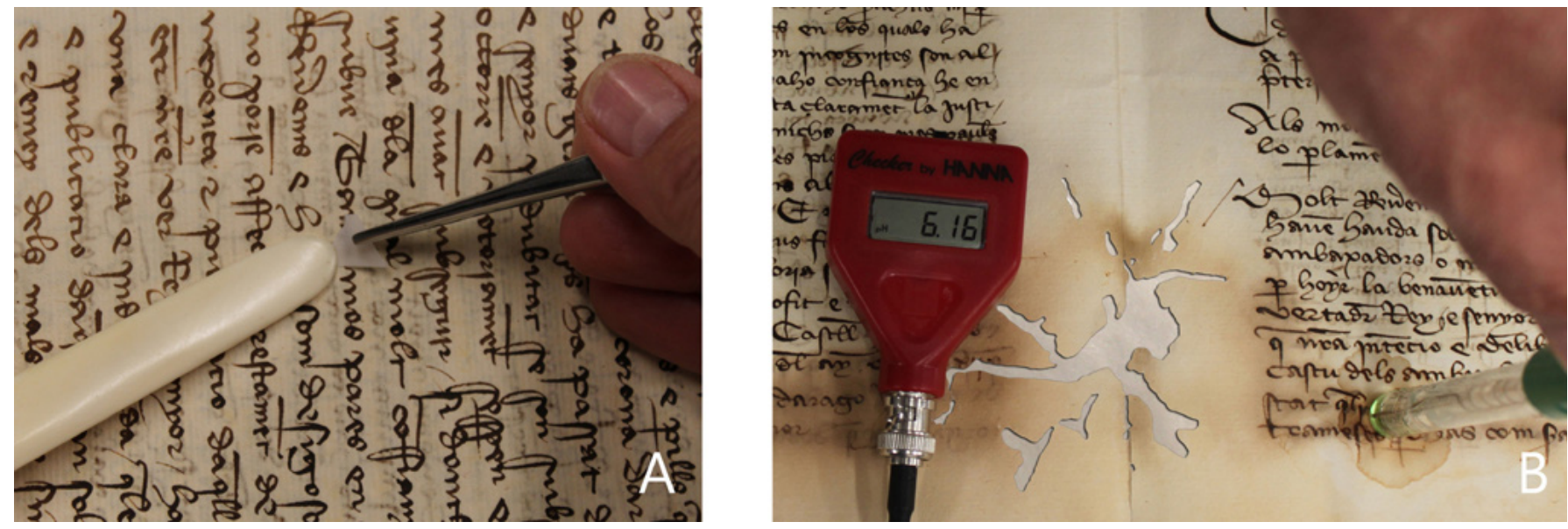

5. Análisis Fe II y pH

A. Detección del ión Fe II f. 47v

B. Medición pH

| fotos Luciano Pardo

es fundamental para determinar si es necesario aplicar algún tratamiento de neutralización o consolidación. La degradación del papel causada por la acción de las tintas ferrogálicas se debe a dos procesos químicos distintos, la oxidación y la hidrólisis ácida de la celulosa. Éstos se producen por diversas reacciones del hierro y azufre de la tinta, que se ven favorecidos y potenciados por la humedad y la temperatura ambiental. Para determinar el nivel de progreso de ambos procesos químicos se han realizado análisis para conocer su estado desde distintas perspectivas: examen visual, grado de oxidación y acidez.

En cuanto al examen visual, se aprecian pequeñas zonas con leve migración, que en algunos casos han llegado a perforar (imagen 4F), y también abundantes y extensas zonas empalidecidas o con disoluciones (imagen 4G, H).

El grado de oxidación de la tinta se revela por la presencia del ión $\mathrm{Fe}^{2+}(\mathrm{Fe} \mathrm{II})$. Para ello se ha realizado un test con tiras indicadoras de papel impregnadas de Batofenantrolina, que reaccionan ante la presencia de óxido adquiriendo un color magenta (ROUCHON, 2007). Se han comprobado varias zonas de tinta con trazos de diferentes características. En todos los casos la presencia de $\mathrm{Fe}^{2+}$ no es significativa (imagen $5 \mathrm{~A}$ ).

Para analizar el grado de acidez se han realizado cinco mediciones de $\mathrm{pH}$ en distintas hojas con probabilidad significativa de acidez, siguiendo el procedimiento recogido en la norma T529. (TAPPI T 529 om-09, 2009). Los valores registrados se sitúan entre $\mathrm{pH} 5,70$ y $\mathrm{pH} 6,23$, por lo que podemos considerar que la tinta presenta un grado de acidez moderado (imagen 5B).

Las tintas ferrogálicas se componen de tres ingredientes principales disueltos generalmente en agua: taninos, vitriolo (sulfato ferroso) y gomas (general- 
mente goma arábiga) (EUSMAN, 1998). La proporción de estos ingredientes da como resultado tintas con características divergentes. Dados los resultados de los análisis (bajo nivel de oxidación, moderado grado de acidez) y por las características visuales de la tinta, podemos deducir que la tinta del documento es una tinta desbalanceada al tanino. Es decir, el contenido de hierro con relación al contenido de taninos es menor que la proporción equilibrada 3.6:1 (m/m) de hierro/tanino (POTTHAST; HENNIGES; BANIK, 2008). Presenta por tanto un exceso de tanino que actúa como protección ante la oxidación, resultando una tinta menos ácida y con menor poder de oxidación, que adquiere un tono café amarillo y tiende a la decoloración y disolución.

\section{INTERVENCIÓN}

\section{Criterios}

La información potencialmente deducible de un documento original es una cualidad difícilmente "reproducible", porque obviamente no se limita exclusivamente al mensaje textual o a su apariencia, sino también a su constitución. El documento original permite deducir, además de información textual, información cultural, histórica, artística, tecnológica, etc:

$>$ A través de los materiales que lo conforman: por sus características, composición, método de fabricación del papel, tintas, pieles, adhesivos, hilos, etc.

> Mediante la tecnología utilizada en la creación del documento: estructura, cuadernillos, costura, cabezadas, guardas, encuadernación, estilo de la escritura, adornos; también las personas, fabricantes, lugares, momento histórico, etc.

$>$ Por todas las huellas que ha dejado el paso del tiempo: modificaciones en su estructura, añadidos, pérdidas, mutilaciones, reparaciones, reencuadernaciones, disoluciones, ataques de insectos, desastres, etc.

La información contenida en el documento no siempre es evidente. Sin embargo en el futuro, nuevas técnicas de análisis y de investigación pondrán al descubierto información que no nos imaginamos. Un ejemplo, es la aportación de las investigaciones del profesor Gimeno sobre la originalidad del manuscrito varios siglos después de su creación (GIMENO, 2009).

Nuestro criterio principal es, por tanto, preservar la originalidad del documento para mantener la máxima información: evitando tratamientos generalizados que afecten indiscriminadamente a toda la obra; realizando los tratamientos absolutamente necesarios y limitados a las áreas afectadas, 
2

"Keeping the relative humidity under $60 \%$, and handling with care are the most effective strategies to prolong the existance of originals made with iron gall ink" < http://irongallink. org/igi_index172f.html> Mantener la humedad relativa por debajo del $60 \%$ y la manipulación adecuada del documento son las estrategias más eficaces para prolongar la existencia de los originales realizados con tintas ferrogálicas. para estabilizar, consolidar y conferirle funcionalidad; con el máximo grado de reversibilidad tanto en los materiales añadidos como en la tecnología empleada en su inserción; y evidenciando las zonas intervenidas.

\section{Proceso de restauración}

A tenor de la constitución material y tecnológica de la obra, de la diagnosis de su estado de conservación y ateniéndonos a los criterios expuestos anteriormente, el proceso de restauración del documento se desarrolla en varias fases.

\section{Tratamientos que se han desestimado}

Determinar los tratamientos que se excluirán en el proceso de restauración es tan importante como la elección de los tratamientos que serán aplicados. En este caso los tratamientos que se han desestimado son:

$>$ Lavado. Los beneficios del lavado en este documento (eliminación de algunos ácidos y manchas solubles, mejora de la resistencia física del papel) son menores que sus inconvenientes: disolución de tintas, aprestos, satinado y deformación del soporte.

> Desacidificación. El tratamiento se excluye basándose en la acidez moderada de la tinta; por la buena calidad del papel (sus condiciones físicas y químicas, como el alto contenido en $\mathrm{Ca}$ ); para preservar la originalidad del documento al no añadir materiales extemporáneos; y porque existe un control adecuado del medio ambiente en los depósitos de la biblioteca, condición indispensable para disminuir la velocidad de los procesos químicos de degradación de los materiales².

$>$ Tratamientos fungicidas o desinsectación. No se realiza ningún tratamiento por la ausencia de actividad biótica en la actualidad.

\section{Desmontaje}

Los cuadernillos se encontraban prácticamente sueltos porque no se utilizó ningún adhesivo en la encuadernación. El desmontaje por tanto ha consistido básicamente en la extracción de los restos de hilos de la costura y la separación de las hojas.

\section{Limpieza mecánica}

El documento no contiene excesiva suciedad de materiales pulverulentos, salvo en las primeras y últimas hojas y en el interior de los pliegues de algunos cuadernillos.

Para la eliminación de estos residuos, sueltos o adheridos, se ha utilizado la abrasión con bisturí y gomas de borrar de diferentes durezas. Finalmente se realiza una suave aspiración mediante aspirador (Muntz vacuumcleaner) con boquilla de pelo de cabra en las zonas que lo permiten. En las más frágiles se evita cualquier acción o se utiliza únicamente un pincel suave. 

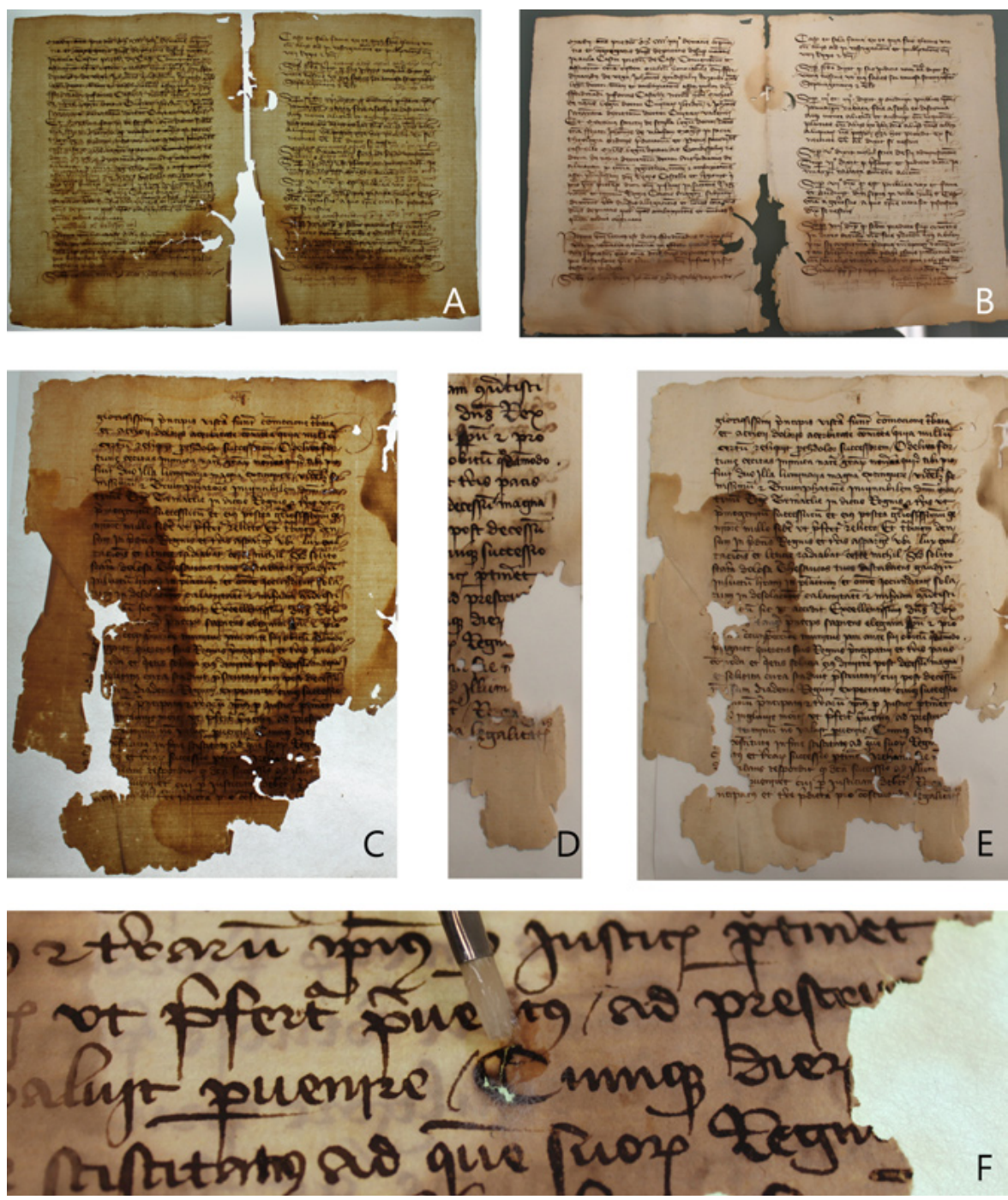

\section{Reparación de grietas, desgarros y refuerzo de pliegues}

La unión de grietas, desgarros y fragmentos de soporte se realiza manualmente con papel japonés de fibras de kozo de $9 \mathrm{gr} / \mathrm{m}^{2}$, mientras que para el refuerzo del pliegue en los bifolios externos se usa de $15 \mathrm{gr} / \mathrm{m}^{2}$. Como adhesivo se utiliza metilhidroxietilcelulosa (MHEC, Tylose $^{\circledR}$ MH 300p) al $2 \%$ en agua, fijado mediante espátula termostática (imagen 6A, B).

\section{Colocación de fragmentos gráficos y soporte}

En las zonas con grafía se utiliza papel japonés de fibras de Kozo de $6 \mathrm{gr} / \mathrm{m}^{2}$ (imagen 6C-E e imagen 6F).

\section{Reintegración del soporte}

Las alternativas técnicas disponibles para la reintegración del soporte de
6. Intervención

A. Imagen por transparencia, estado antes de la intervención f. $49 \mathrm{v}-72 \mathrm{r}$.

B. Unión y refuerzo del pliegue, grietas y desgarros. Alisado de arrugas f. 49v - 72r.

C. Colocación de fragmentos f. $2 v$ imagen por transparencia antes de la intervención.

D. Detalle del fragmento insertado

E. Hoja reparada f. $2 v$.

F. Consolidación de perforaciones de tinta y zonas frágiles f. $2 \mathrm{v}$.

fotos Luciano Pardo 
documentos (reposición de papel en las zonas desaparecidas o lagunas) se reducen básicamente a dos: manual y mecánica (mediante inmersión en reintegradora). La manual es la más antigua y eficaz pero su realización es bastante costosa debido al tiempo que es necesario invertir en adaptar un papel ya formado e integrarlo en las zonas desaparecidas del documento. La reintegración mecánica tiene como ventaja principal la rapidez de ejecución, sin embargo tiene una serie de inconvenientes que desaconsejan su utilización en muchos casos y que consideramos a continuación:

$>$ Disolución en mayor o menor grado de aprestos y tintas, eliminación del satinado, etc. debido a la necesidad de sumergir el documento en agua.

$>$ Variación de dimensiones del papel debido a la cantidad de agua que absorben las fibras. Estas dimensiones no se recuperan completamente después del secado.

$>$ Deformación por prensado, eliminación de texturas e improntas. El documento húmedo es muy sensible a deformaciones causadas por la presión, es muy probable la eliminación de la impronta de los tipos en documentos impresos.

$>$ Precipitado de fibras en toda la superficie, mayor cuanto más poroso sea el papel.

> Precipitado de nuevos adhesivos del reapresto sobre toda la superficie del papel.

$>$ La reintegración mecánica es uno de los principales argumentos para desencuadernar muchos libros y documentos que pierden irremediablemente una parte importante de su información y por tanto de su originalidad.

\section{Reintegración mecánica en seco}

La técnica que se ha desarrollado como alternativa a las anteriores consiste en la reintegración mecánica de lagunas mediante la absorción de fibras de celulosa, utilizando como vehículo de transporte el aire en substitución del agua. El sistema cuenta con varios dispositivos que se encargan de la mezcla y acondicionamiento de las fibras (imagen $7 \mathrm{~A}$ ) y de su transporte hacia la zona de succión mediante campana difusora (imagen 7B).

\section{Procedimiento}

El trabajo se inicia colocando el documento sobre un filtro en la mesa de succión (imagen 7C). A continuación, se sitúa la campana difusora transparente sobre la zona a reintegrar y se activa la succión para atraer las fibras hacia las zonas libres del soporte o lagunas (imagen 7D). En caso necesario se pueden descubrir zonas con grafía ocultas por fibras (imagen 7E).

Para la reintegración se ha utilizado la siguiente mezcla: 50\% lino, 25\% cáñamo y $25 \%$ algodón, para obtener un injerto con características físicas similares al original. La fijación y consolidación de la reintegración se efectúa 

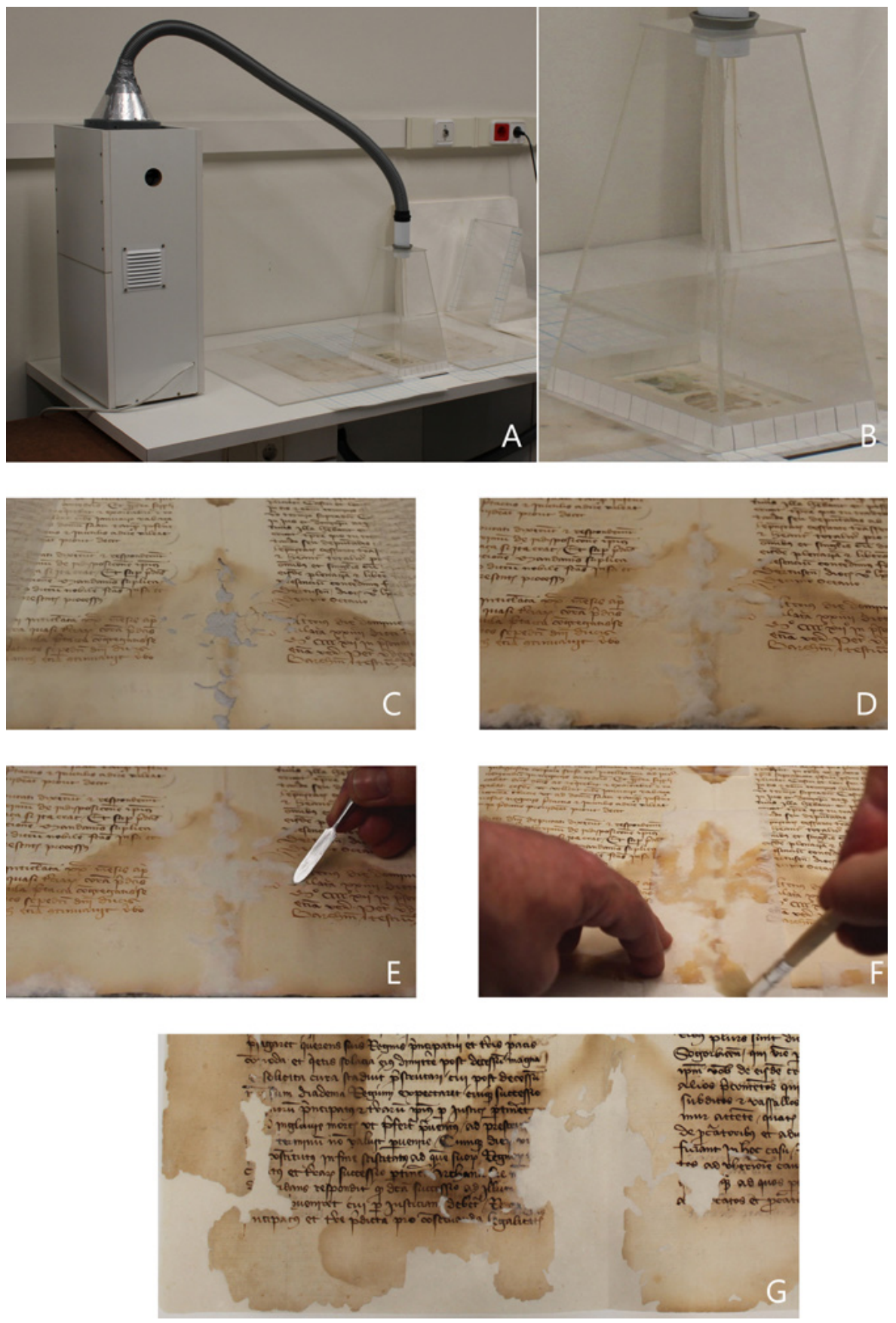

mediante MHEC al 2\% en solución hidroalcólica 15\% agua y $85 \%$ isopropanol (TACÓN, 2009), aplicado con pincel a través de un reemay para evitar el arrastre de fibras (imagen 7F). La elevada proporción de alcohol en el adhesivo evita la dilatación del soporte, la aparición de aureolas y la disolución de tintas, aprestos, etc. A continuación se coloca entre secantes y tableros con
7. Reintegración en seco

A. Dispositivos de mezcla y acondicionamiento de fibras y campana de difusión.

B. Detalle de la campana.

C. Reintegración en seco, documento sobre el filtro en la mesa de succión f. 33v - 40r.

D. Las fibras de celulosa han cubierto lagunas en la zona tratada.

E. Se descubren algunas zonas de grafía cubiertas por las fibras junto a laguna.

F. Aplicación de adhesivo: solución hidroalcólica MHEC al $2 \%$ aplicado a pincel a través de un reemay para evitar el arrastre de fibras.

G. Detalle de una zona reintegrada f. $2 v-23 r$.

fotos Luciano Pardo 
8. Intervención de la encuadernación

A. Limpieza mecánica.

B. Reparación desgarros e injertos.

C. Inicio de la costura, primer cuadernillo.

D. Guarda cosida junto con el primer cuadernillo.

| fotos Luciano Pardo
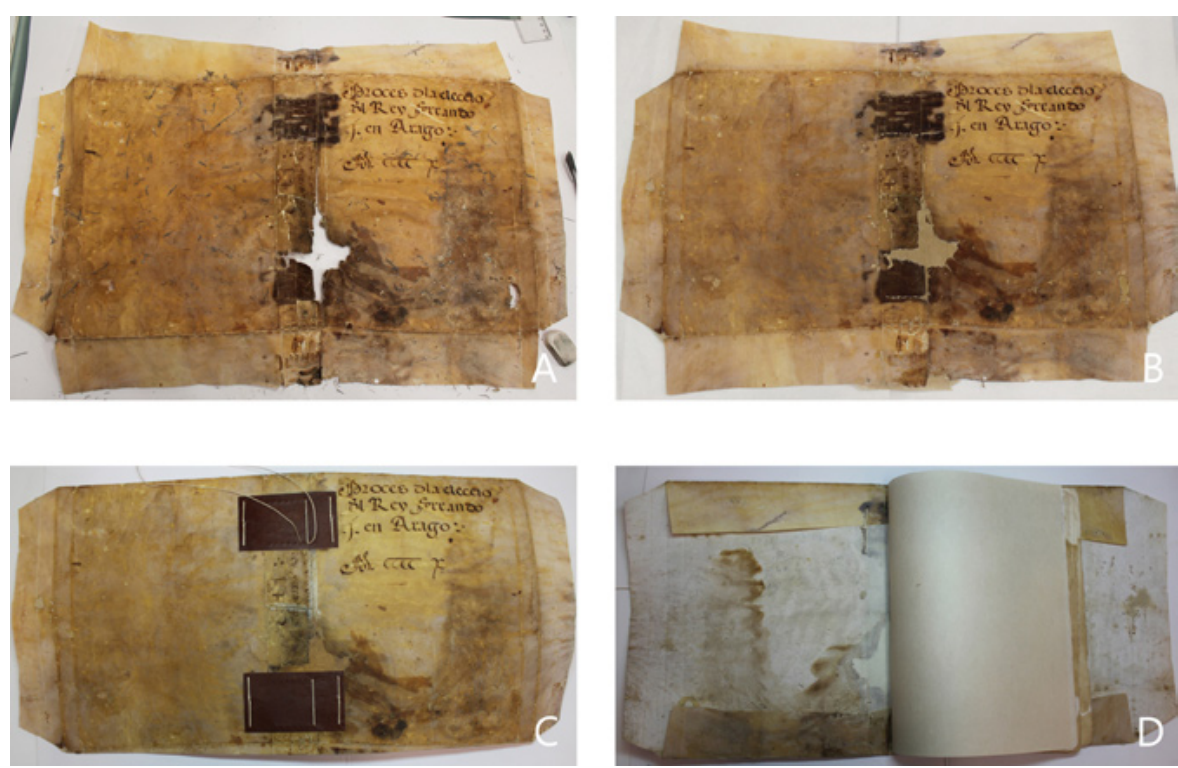

presión moderada hasta el secado final (imagen 7G). Para más información: http://mmedia.uv.es/buildhtml?user=Ipardo\&path=/\&name=reinsec.mp4.

\section{Ventajas de la reintegración en seco}

$>$ Tratamiento localizado y no generalizado como sucede en la reintegración en húmedo, afectando mínimamente a la zona tratada como en la reintegración manual.

$>$ No hay disolución ni eliminación de aprestos, tintas, satinado u otras características originales.

$>$ No hay variación en las dimensiones de los documentos (largo, ancho y espesor del papel).

$>$ No hay deformación por prensado, ni del soporte ni de elementos sustentados. Así, no se eliminan texturas e improntas en documentos impresos o grabados porque la presión se realiza con el soporte seco y a un nivel similar a la reintegración en húmedo. En caso de obras que lo requieran se puede ejercer una presión puntual sobre el injerto.

$>$ No hay adición de materiales contemporáneos en zonas no afectadas, precipitado de fibras en toda la superficie, adhesivos, etc.

$>$ El proceso de reintegración es rápido.

$>$ Permite rectificar en cualquier momento.

$>$ Permite añadir más fibras después de consolidada la reintegración, incluso por ambos lados del soporte.

> La calidad de la zona reintegrada es similar a la reintegración en húmedo.

La mayor aportación de la técnica es sin duda su inocuidad. No hay efectos adversos ni secundarios sobre la integridad original de las obras, ya que la intervención afecta exclusivamente a la reposición de fibras y a su consoli- 
dación en la zona dañada, sin modificar las características físicas o químicas de las zonas colindantes en buen estado. Además la intervención es absolutamente reversible.

Por otro lado se está trabajando en un dispositivo que permita situar el sistema de aspiración entre las hojas del libro, de manera que se pueda realizar el tratamiento de reintegración en seco sin desmontarlo. Esto permitirá intervenir obras con hojas dañadas pero con encuadernaciones y costuras en buen estado. En la actualidad es necesario desmontar estos libros para colocar sus hojas en la reintegradora, con la consiguiente pérdida de originalidad.

\section{Encuadernación}

Para la restauración de la cubierta se ha seguido un proceso de intervención similar al del cuerpo del libro. La limpieza mecánica de la superficie de la cubierta se ha realizado mediante abrasión con bisturí y gomas de diferentes durezas y aspiración final (imagen 8A).

\section{Hidratación}

Instalación del pergamino sobre secantes humedecidos interponiendo una lámina de GoreTex ${ }^{\circledR}$ hasta conseguir la relajación del material. A continuación se coloca el pergamino sobre secantes con ligero peso en el perímetro para el alisado y estiramiento. La zona del lomo (bastante contraído y frágil) hace inviable una recuperación de las dimensiones originales, por lo que el pliegue inferior se realizó de manera que el lomo tuviese la longitud necesaria. Posteriormente se ha procedido a la unión de desgarros con goldbeaters Skin y gelatina. Los injertos se han realizado con pergamino de cabra estabilizado y adherido con gelatina (imagen 8B).

\section{Costura}

Se realiza una costura de archivo siguiendo las huellas coincidentes encontradas en los cuadernillos, en el pergamino y en los refuerzos de piel (imagen 8C). Para proteger la primera y última hoja del documento de las erosiones que provocan los relieves propios de este tipo de encuadernación (aristas del pergamino, nudos de los cierres o hilos de sujeción de los refuerzos de piel) se ha insertado una guarda de papel japonés de fibras de kozo de $71 \mathrm{~g}$ cosida mediante una pestaña junto con el primer y último cuadernillo (imagen 8D). Una vez terminada la costura y realizados los pliegues del corte de delante se insertan los cierres de piel de cabra curtida al alumbre (imagen 9A).

\section{Estuche de conservación}

Realizado con cartón de conservación de 2,2 mm, forrado exteriormente con tela de encuadernación Buckram e interior de papel permanente adherido todo con MHEC. En un sobre adjunto se depositan los restos no insertados en el documento durante la restauración, hilos, refuerzo de piel del lomo, etcétera. 


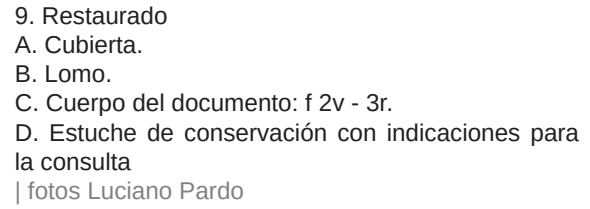

D. Estuche de conservación con indicaciones para

la consulta

| fotos Luciano Pardo
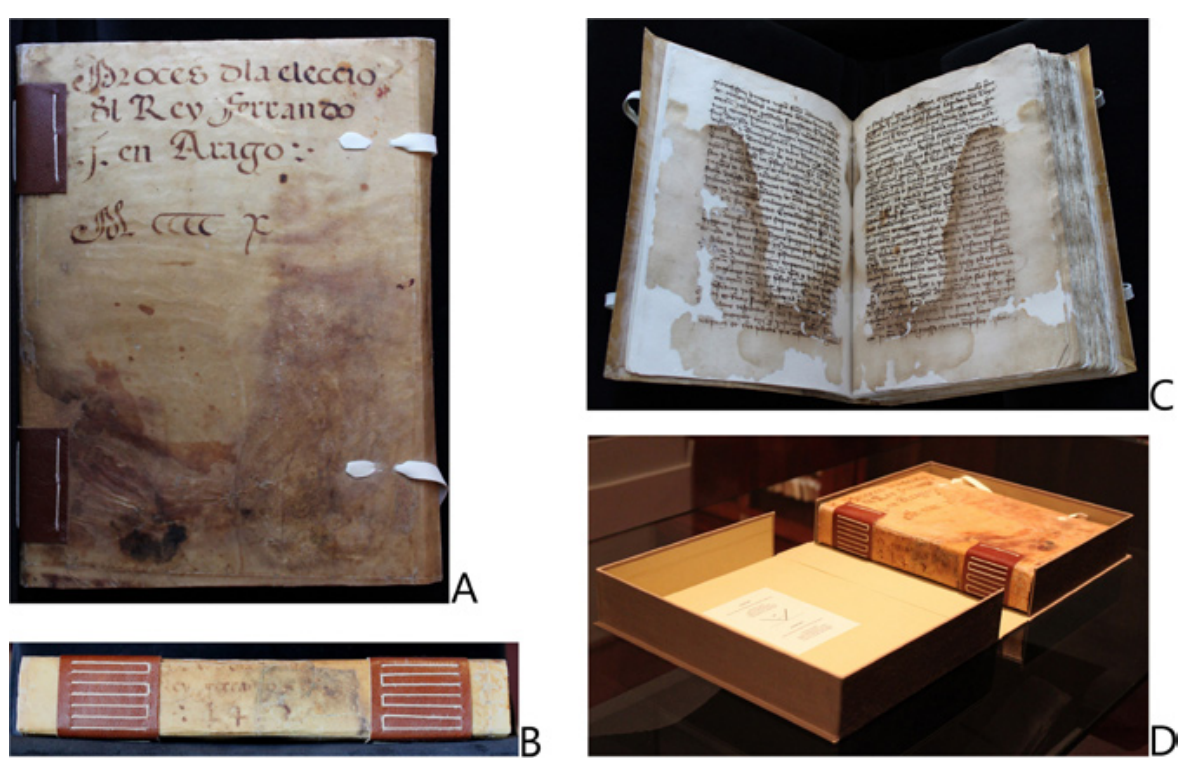

Los detalles del documento restaurado pueden observarse en la imagen (imagen 9A-D).

\section{PRESERVACIÓN DEL PATRIMONIO DOCUMENTAL Y BIBLIOGRÁFICO}

La perdurabilidad de las obras no está garantizada únicamente con la restauración. El control y la mejora de las condiciones de conservación forman, junto con la restauración, el plan integral de preservación del Servei de Biblioteques i Documentació de la Universitat de València. Este plan constituye una herramienta fundamental del trabajo que se viene desarrollando a lo largo de los años y cuyo objetivo primordial es aumentar la esperanza de vida del nuestro patrimonio documental y bibliográfico.

Es necesario subrayar en este punto la importancia del resto de actividades del proyecto, sin las cuales la restauración no tendría la repercusión necesaria en la conservación de nuestro patrimonio bibliográfico. El plan de preservación se lleva a cabo mediante líneas de actuación como: la gestión de programas, el control de las colecciones y su entorno y la intervención sobre objetos individuales.

> La gestión de programas comprende entre otras la creación y aplicación de directrices de preservación entre las que se encuentran:

- Procedimiento de buenas prácticas y principios de uso y manipulación de materiales bibliográficos y documentales.

- Formación de trabajadores y usuarios.

- Protocolo para la preservación del patrimonio durante exposiciones temporales.

- Normas de préstamo. 
- Planificación de desastres.

$>$ El control de las colecciones y su entorno tiene como objetivo:

- La inspección y mejora de instalaciones. En la actualidad se está llevando a cabo una importante reordenación de los fondos de la biblioteca histórica para conseguir mayor funcionalidad, seguridad y sobre todo mejorar las condiciones de conservación.

- El control de los factores ambientales: temperatura y humedad, contaminantes atmosféricos, iluminación, control integral de plagas...

- La protección y mantenimiento de las colecciones, desde su limpieza hasta la protección mediante contenedores.

> La intervención sobre objetos individuales:

- Conservación de la información mediante la reproducción de obras (digitalización).

- Conservación de los materiales físicos mediante la restauración.

Como ejemplo representativo del criterio que se ha seguido en el conjunto de líneas de actuación, analizaremos brevemente la evolución del clima en dos salas de la biblioteca histórica.

\section{"Visualizar el clima"}

Los datos estadísticos y los gráficos convencionales no transmiten generalmente una visión completa de la realidad del clima de nuestras salas y depósitos. Es necesario visualizar infinidad de gráficos para hacernos una idea de la evolución durante varios años e incluso durante períodos más cortos.

Exponemos a continuación un método para mostrar global y pormenorizadamente, de forma simultánea, la evolución del clima de diferentes períodos de tiempo (un año completo o la evolución interanual de más de diez años). Los gráficos se actualizan automáticamente al abrir el programa, importando los datos directamente de los registros acumulados en la base de datos (fecha, hora, temperatura y humedad relativa). En la representación elaborada con estos datos podemos visualizar completamente el "aspecto" que tiene el clima de nuestra sala o depósito y cuantificar en días si dicho clima es adecuado o adverso. Además, tenemos gráficos anuales que recogen con detalle la proporción de días por mes con un clima determinado y gráficos que recogen el resumen interanual. El "aspecto" del clima se representa según un código de colores que se muestra en la leyenda adjunta (imagen 10).

Cuando aparecen en el gráfico los colores que representan una $\mathrm{Hr}$ superior al $60 \%$ y una temperatura mayor de $22^{\circ} \mathrm{C}$ se alerta sobre un serio riesgo de brote de hongos, de pérdida de resistencia mecánica de algunos materiales, de riesgo de oxidación sobre todo en metales, incluidos los que componen las tintas. 
10. Conservación

A. Clima de la sala de exposiciones desde 2001

a 2013. Se representan pares simultáneos de Ty HR en días, según diferentes rangos, indicados en leyenda adjunta. Oscilaciones detectadas de T y HR en días. Promedios de T y HR. Nivel de permanencia o esperanza de vida en $\%$.

B. Detalle del año 2012 por meses. Puede observarse el promedio de temperatura y HR por meses y su evolución según las épocas. Los meses con menor esperanza de vida son los de verano al coincidir la T y HR más altas.

C. Clima de la sala de consulta, desde 2001 a 2013. El clima es visiblemente distinto a la sala anterior. El control se ha realizado con un criterio distinto debido al uso compartido del espacio por fondos y por personas. Esto obliga a mantener unos niveles de temperatura superiores.

| gráficos Luciano Pardo

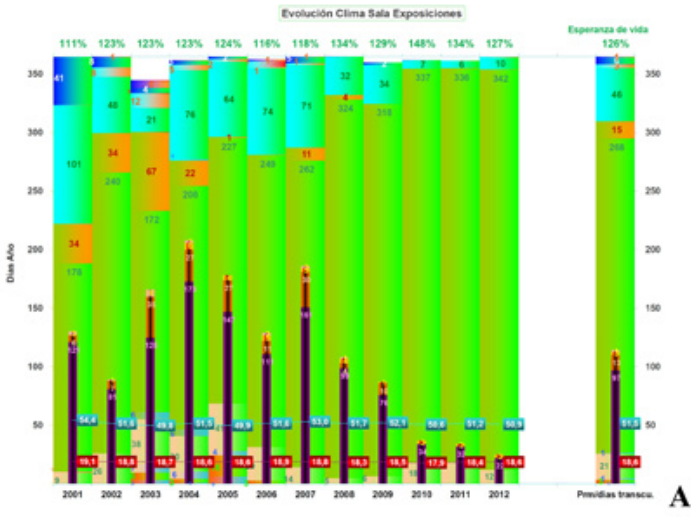

\section{$\square \sin$ datos}

dias $>60 \% \mathrm{y}>22^{\circ} \mathrm{C}$

dias $>60 \% \mathrm{y}>20-22^{\circ} \mathrm{C}$

dias $>60 \%$ y $16-20^{\circ} \mathrm{C}$

dias $>60 \%$ y $13<16^{\circ} \mathrm{C}$

dias $>60 \% \mathrm{y}<13^{\circ} \mathrm{C}$

dias $>55-60 \% \mathrm{y}>22^{\circ} \mathrm{C}$

dias $>55-60 \%$ y $>20-22^{\circ} \mathrm{C}$

dias $>55-60 \%$ y $16-20^{\circ} \mathrm{C}$

dias $>55-60 \%$ y $13-<16^{\circ} \mathrm{C}$

dias $>55-60 \% \mathrm{y}<13^{\circ} \mathrm{C}$

dias $45-55 \% \mathrm{y}>22^{\circ} \mathrm{C}$

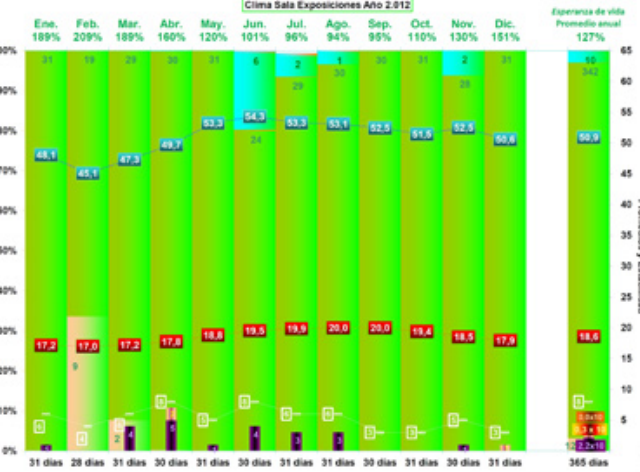

dias $45-55 \% \mathrm{y}>20-22^{\circ} \mathrm{C}$

dias $45-55 \%$ y $16-20^{\circ} \mathrm{C}$

dias $45-55 \%$ y $13-<16^{\circ} \mathrm{C}$

dias $45-55 \% \mathrm{y}<13^{\circ} \mathrm{C}$

dias $35-<45 \% \mathrm{y}>22^{\circ} \mathrm{C}$

dias $35-<45 \%$ y $>20-22^{\circ} \mathrm{C}$

días $35-<45 \%$ y $16-20^{\circ} \mathrm{C}$

dias $35-<45 \%$ y $13-<16^{\circ} \mathrm{C}$

dias $35-<45 \%$ y $<13^{\circ} \mathrm{C}$

dias $<35 \%$ y $>22^{\circ} \mathrm{C}$

dias $<35 \%$ y $>20-22^{\circ} \mathrm{C}$

dias $<35 \%$ y $16-20^{\circ} \mathrm{C}$

dias $<35 \%$ y $13-<16^{\circ} \mathrm{C}$

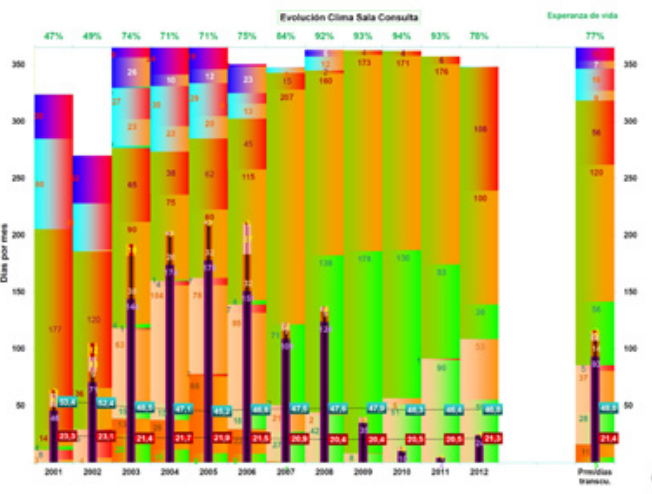

dias $<35 \%$ y $<13^{\circ} \mathrm{C}$

I. $\operatorname{Var} T>2,5$

II $\operatorname{Var} \mathrm{T}>1$

Var $>10$

Var $>5$

-...... Prom $\mathrm{H}$

Prom T

Max Var Hr

- Prom InterAnual $\mathrm{Hr}$

= Prom InterAnual T

Cuando aparecen los colores que representan una $\mathrm{Hr}$ inferior al 35\% y una temperatura superior a $22^{\circ} \mathrm{C}$ se alerta sobre un serio riesgo de pérdida de resistencia mecánica de los materiales.

El gráfico (imagen 10A) resume el clima interanual en una de las salas desde el año 2001 hasta la actualidad. En él puede observarse fácilmente como las 
columnas en dos tonos verdes (representan el clima ideal en pares de temperatura $(T)$ y humedad relativa $(H R)$ registrados simultáneamente y comprendidos entre $18 \pm 2{ }^{\circ} \mathrm{C} \mathrm{T}$ y entre $50 \% \pm 5 \% \mathrm{HR}$ ) van ocupando mayor superficie con el paso de los años, hasta alcanzar 342 días en el año 2012 frente a 178 del año 2001. Por el contrario el clima desfavorable registrado en 2001 (41 días con HR superior al 60\% y 34 días con T entre 20 y $22{ }^{\circ} \mathrm{C}$ ) ha ido disminuyendo hasta desaparecer en el 2009.

La columna más delgada dentro del mismo año representa la estabilidad en días, con registro de oscilaciones de HR mayor de 5\% y de 10\% durante 24 horas y oscilaciones de T mayor de $1^{\circ} \mathrm{C}$ y $2,5^{\circ} \mathrm{C}$ en el mismo periodo. En el año 2012 se han registrado sólo 22 días con oscilaciones entre 5 y 10\% de HR y 3 días con oscilaciones entre 1 y $2,5^{\circ} \mathrm{C}$. La estabilidad ha mejorado considerablemente.

La esperanza de vida (mostrada en el eje horizontal superior) se calcula aplicando una fórmula (SEBERA, 1994) que nos da idea de la velocidad con que se produce el deterioro químico ocasionado por la temperatura y la humedad.

$$
\frac{r_{2}}{r_{1}}=\left(\frac{R H_{2}}{R H_{1}}\right)\left(\frac{T_{2}+460}{T_{1}+460}\right) 10^{-394 \Delta H^{\neq}\left(\frac{1}{T_{2}+460}-\frac{1}{T_{1}+460}\right)}
$$

En esta fórmula se toma como unidad de deterioro una $\mathrm{T}$ de $20^{\circ} \mathrm{C}$ y $\mathrm{HR}$ de $50 \%$, es decir, con este clima el grado de deterioro es $r=1$ y le corresponde una isoperma o nivel de permanencia también de 1. Podríamos decir que un nivel de permanencia 1 equivale a una esperanza de vida del 100\%. Si reducimos la $\mathrm{T}$, la $\mathrm{HR}$ o ambos parámetros, reduciremos la velocidad de las reacciones químicas de degradación de los materiales y tendremos como resultado un grado de deterioro menor. Si el valor de deterioro fuese la mitad que el anterior, la isoperma o esperanza de vida sería el doble ${ }^{3}$.

Con esta fórmula podemos conocer, además de la velocidad de deterioro químico de nuestras colecciones, la consigna de temperatura y humedad relativa idónea en cada época del año, para conseguir un clima adecuado y sostenible, dentro de los rangos recomendables (imagen 10B). La variable más fácil de controlar es la temperatura; por esta razón es conveniente mantener la temperatura en el rango inferior durante el invierno y en el rango superior durante el verano. De esta manera conseguiremos mayor estabilidad y al mismo tiempo menos gasto de energía. La HR en un espacio cerrado varía de manera inversa al grado de temperatura; es decir, con la misma humedad absoluta, al bajar la temperatura, sube la humedad relativa $y$, al subir la temperatura, baja la humedad relativa. El invierno en nuestra
Si el valor de $r 2$ fuese la mitad de r1, entonces $r 2 / r 1=0,5 / 1=0,5$ es decir, el grado de deterioro sería la mitad $50 \%$ y la isoperma o esperanza de vida aumentaría el doble: $1 / 0,5=2$ es decir el 200\%. Entendiendo una esperanza de vida del $100 \%$ como la esperanza de vida media de cada material. 
11. Vista de una de las salas con uso compartido como sala de exposiciones y depósito de libros | foto Luciano Pardo

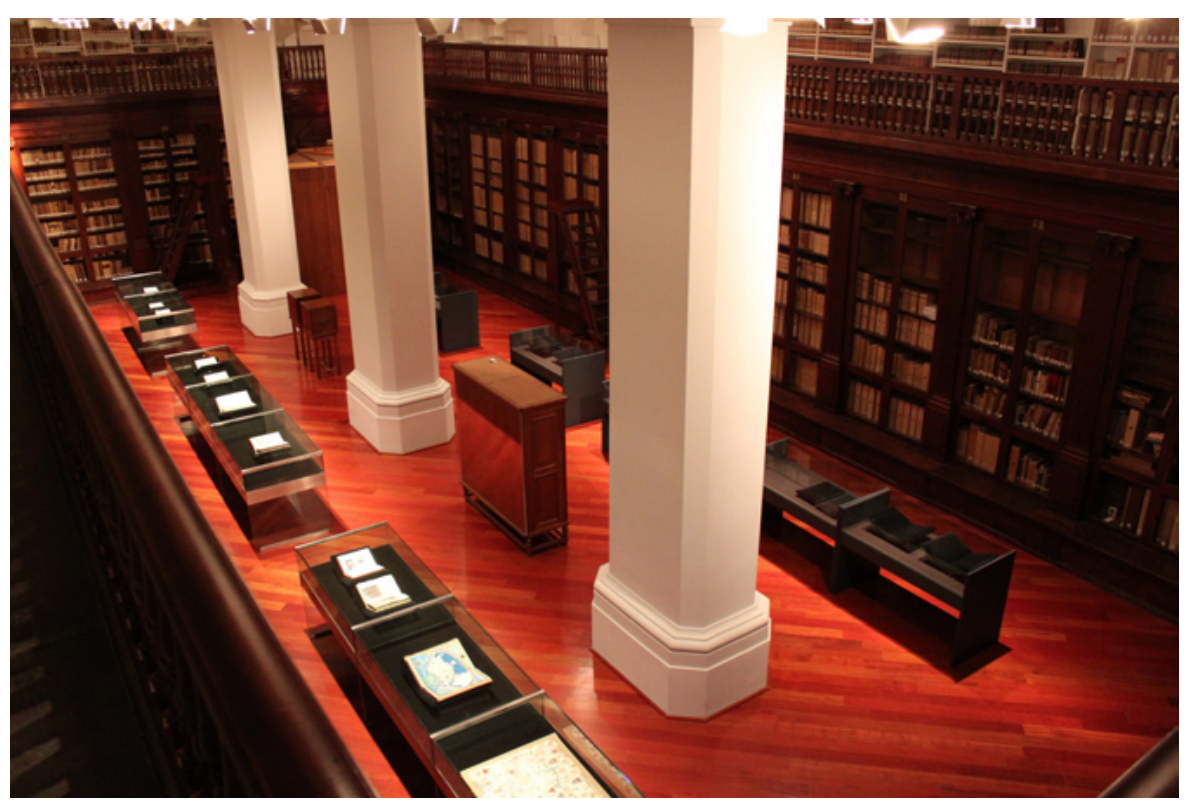

zona geográfica es la época más seca y en la que más tiempo suelen actuar los humidificadores. Mantener la temperatura en el rango inferior implica obtener el mayor grado de humedad posible, por lo que evitaremos muchas horas de actividad de estos aparatos. Por el contrario, el verano es la época más húmeda y cuando más necesarios son los sistemas de deshumidificación, es la época del año en la que más energía consumimos. Mantener la temperatura en el rango superior implica obtener el menor nivel de humedad posible, y favorecer el tratamiento del aire en la deshumectación.

En el gráfico correspondiente a la sala de consulta (imagen 10C) puede apreciarse igualmente cuál ha sido la evolución del clima. Los primeros años había un control mínimo sobre el clima. La tendencia era hacia un clima cálido en invierno y cálido y húmedo en verano. Durante los primeros años la esperanza de vida de los fondos en este espacio era inferior al 50\%. En los años siguientes comprobamos cómo disminuyen los promedios de T y HR y aumenta la esperanza de vida, aunque todavía no se tiene un control sobre la estabilidad. En el año 2009 se consigue un equilibrio adecuado tanto en el clima como en la estabilidad y esperanza de vida. Las numerosas quejas de usuarios y trabajadores por la temperatura durante los meses de verano (entre 22 y $23^{\circ} \mathrm{C}$ ) hacen replantear nuestro criterio y buscar alternativas para mejorar la conservación del fondo y el confort para los usuarios.

En la actualidad existe un proyecto para trasladar los fondos más valiosos a depósitos más reducidos y funcionales, más protegidos contra desastres, y en definitiva más eficientes. 


\section{BIBLIOGRAFÍA}

- ARDID, M.; FERRERO, J. L.; ROLDÁN, C et ál. (2004) Design of EDXRF equipment for the non destructive study of prints. Advances in X-ray Analysis. ICDD, vol. 47, pp. 70-75

- BRIQUET, C. M. (1966) Les filigrannes. Dictionnaire historique des marques du papier des leur apparition vers 1282 jusqu'en 1600. Deuxième édition. New York: Hacker Art Books, 1966

- DUALDE, M.; CAMARENA, J. (1971) El Compromiso de Caspe. Zaragoza: Institución "Alfonso el Magnánimo". Diputación Provincial de Valencia. Institución "Fernando el Católico". Diputación Provincial de Zaragoza, 1971, pp. 4649

- EUSMAN, E. (1998) Iron gall ink - Ingredients. The Iron Gall Ink Website <http://ink-corrosion.org/igi_indexee73. html> [Consulta 30/03/2014]

- FERRERO, J. L.; ROLDÁN, C.; JUANES, D. et ál. (2004) Study of inks on paper engravings using portable EDXRF spectrometry Nuclear Instruments and Methods B213 729. Nuclear Instruments and Methods in Physics Research Section B, vol. 213, pp. 729-734

- GIMENO, F. M. (2009) Un Diario Original Desconocido del Compromiso de Caspe en la Universidad de Valencia. Saitabi: revista de la Facultat de Geografia i Història, n. ${ }^{\circ}$ 59, 2009 (Ejemplar dedicado a: Homenatge al professor Dr. Pedro López Elum), pp. 319-325 <http:// roderic.uv.es/bitstream/handle/10550/27311/319-325. pdf? sequence $=1>$ [Consulta 6/02/2014]

- POTTHAST, A.; HENNIGES, U.; BANIK, G. (2008) Iron gall ink-induced corrosion of cellulose: aging, degradation and stabilization. Part 1: model paper studies. Cellulose, diciembre 2008, vol. 15, n. ${ }^{\circ}$ 6, pp. 849-859 <http://link. springer.com/article/10.1007\%2Fs10570-008-92371\#page-1> [Consulta 6/06/2013]

- ROLDÁN, C. (2011) Análisis Elemental de la composición de papeles y tintas mediante "EDXRF" del manuscrito Ms. 40 de la Universitat de València. Informe inédito. Valencia: Instituto de Ciencia de los Materiales, Universitat de València, 2011

- ROUCHON, V. (2007) Identification d'une Encre Ferrogallique: Le Test du Fer II. Centre de Recherche sur la Conservation des Collections, Diciembre, $2007<$ http://www. crcc.cnrs.fr/IMG/pdf/testdufer.pdf> [Consulta 6/06/2013]

- SEBERA, D. (1994) Isoperms Combined Effects of T and \% RH. En Isoperms-An Environmental Management Tool, Junio 1994 <http://www.clir.org/pubs/reports/isoperm/ isop-com.html> [Consulta 6/06/2013]

- SOldEVILA, F. (1971) El Compromís de Casp(Resposta al Sr. Menéndez Pidal). Segona edició. Barcelona: Rafael Dalmau editor, 1971, pp. 31-35

- TACóN, J. (2009) Restauración de un libro gravemente deteriorado: Índice de la Librería de la Condesa de Campo de Alange 1779. PH Boletín del IAPH. febrero 2009, n. ${ }^{\circ}$ 69, pp. 112-125 <http://www.iaph.es/revistaph/index.php/ revistaph/article/view/2704/2704> [Consulta 6/06/2013]

- TAPPI T 529 om-09 (2009). Surface pH measurement of paper. Technical Association of the Pulp and Paper Industry. Atlanta 2009 <http://www.tappi.org/Downloads/ Test-Methods/UNTITLED-0104T529pdf.aspx> [Consulta 2/02/2014] 